Artículos 



\title{
Política, justicia, educación
}

\author{
Manuel-Reyes Mate
}

L

o que sigue son fragmentos, pensamientos fragmentados. Nacen de la insatisfacción que produce el pensamiento políticamente correcto hoy dominante tanto en el centro derecha como en el centro izquierda. Hay dos maneras de pensar o de escribir: mirando a la pared (a la pared en la que está fijada la biblioteca llena de libros), es decir, mirando a las ideas de los libros, o mirando a la vida, pensando los problemas de la vida que casi siempre están por delante de los libros y de las ideas de los libros. Estos fragmentos, pese a su tono abstracto, nacen de una observación de la política y de aquellos libros que han surgido de experiencias extremas.

Lo dicho no debería levantar expectativas sino achicarlas dada la dificultad de llevar adelante la empresa. El pensamiento políticamente correcto puede hacer grandes discursos, discursos teóricamente coherentes, porque tiene tras de sí siglos de historia, instituciones que lo avalan, sistemas de educación y de investigación que lo reproducen y medios de comunicación que lo hacen ser creíble. Los fragmentos, por el contrario, sólo se apoyan en restos, en ruinas y bastante tienen con aludir o insinuar el perfil del continente sumergido.

\section{Política}

1. Vivimos tiempos de despolitización, de vaciamiento de la política. Ésta es una afirmación arriesgada, pues lo que resulta evidente es la presencia asfixiante de la política: domina los medios de comunicación, ha pactado con el dinero, tiene a su disposición el derecho... ¿Qué se quiere decir entonces? Que la política se reduce a formalismos, a formas, al respeto de instituciones y formalidades. No pretendo resucitar el viejo debate entre democracia formal y material. En ese debate lo que importaba era poner sobre la mesa lo que le faltaba a la democracia formal para ser una verdadera democracia. A mí, lo 
que me importa ahora es llamar la atención sobre el hecho de que la política ha quedado petrificada en unas determinadas formalidades que corren el riesgo de perder de vista el impulso político que las pusieron en marcha.

¿Qué se ha perdido? La razón o la motivación para luchar por valores en los que, sin embargo, sí creemos. Creemos, por ejemplo, en la libertad y en la justicia, pero no vemos razón alguna para luchar por ellos. Es una extraña paradoja: no nos imaginamos otro sistema político en el que pudiéramos vivir que el democrático y, pese a ello, no movemos un dedo en su defensa, no estamos dispuestos a dar nada propio por él. Naturalmente que pensamos que hay que defender a la democracia pero entendemos que su defensa y mantenimiento es cosa de las instituciones. Cada cual tiene bastante con pagar los impuestos. Con ese dinero bien se puede contratar una empresa de mantenimiento, aunque sea de la democracia y sus valores. Nos hemos quedado con el poder político y hemos perdido la genealogía de los contenidos democráticos. ${ }^{1}$

La pérdida de razones de luchar por los valores democráticos quizá se deba a lo siguiente: en el fondo estamos convencidos de que tales valores son evidentes y consustanciales a nuestro tiempo; forman parte de nuestra vida como las montañas y los ríos. Esa evidencia se debe a que quedan lejos experiencias negativas, experiencias de dictadura o miseria: el ciudadano que ha nacido en democracia no sabe lo que es falta de libertad y miseria social. Vive en un mundo aceptable en el que la miseria y la opresión son camufladas o exportadas. Viajan de noche, como las funerarias, para no amargar el día con el espectáculo de la muerte. A eso habría que añadir, por lo que respecta a la situación española, el mismo argumento que hemos puesto para olvidar el pasado en aras de la convivencia. ${ }^{2}$

2. No hay experiencias negativas. No es una ocurrencia mía esta de la pérdida de experiencia. Es un tema mayor en muchos escritores y pensadores que denuncian esa pérdida porque la constatan en la vida cotidiana.

a) Se suele citar mucho una frase de Walter Benjamin - un autor que con Kafka está muy presente en estas reflexiones- sobre el particular: "somos pobres en experiencia comunicable". ${ }^{3}$ Lo decía curiosamente observando a los soldados que volvían rotos a sus casas después de la terrible experiencia de la Primera Guerra Mundial: ¿cómo podía decir de alguien que había vivido tanto en unos pocos años que era "pobre en experiencia"? Pues porque

\footnotetext{
${ }^{2}$ Felipe González defiende ese olvido como pieza fundamental de la democracia española en El País, 22 de abril de 2001.

${ }^{3}$ Walter Benjamin, "Experiencia y pobreza", en Discursos interrumpidos. Madrid, Taurus, 1973, p. 168.
}

${ }^{1}$ Cf. Helmut Dubiel, Ungewissheit und Politik. Fráncfort, Suhrkamps, 1994, pp. 64 y ss. 
Benjamin distinguía entre vivencias y experiencias. No son lo mismo. La experiencia supone una trama, una red en la que insertar una vivencia que necesita tiempo para insertarse en esa textura y formar parte de ella; la vivencia, por el contrario, es un shock, un enjambre de segundos, una sacudida, un impacto que se agota en sí mismo. No necesita ni de tiempo ni de textura.

Pues bien, los nuestros son tiempos de vivencias, no de experiencias por la sencilla razón de que lo que cada cual vive no pasa a formar parte de la trama de la historia. Ésta se hace sin contar con nosotros. Examinemos la jornada de un urbanícola que bien puede ser cualquiera de nosotros: una buena parte del día se va en escuchar noticias, malas noticias, en general, que se producen, eso sí, lejos de nosotros; las oímos mientras comemos y las digerimos con la misma facilidad con la que damos cuenta del solomillo. No nos afectan. Otra parte del día se la lleva el tráfico que discurre entre el aburrimiento mortal del embotellamiento o entre la velocidad vertiginosa de la carretera. En ambos casos, lo que domina es la mente en blanco. No faltará acercarse a algún establecimiento oficial o pasar por el banco. Ahí nos espera la cola que sólo genera impaciencia por acabar y marcharse. Obligado es ir al supermercado por el que desfilamos entre estantes llenos de productos; con gestos mecánicos trasladamos productos del estante al carro de la compra mientras nos aproximamos impacientemente a la cola de la caja...

¿Qué nos queda de toda esa variedad de situaciones cuando volvemos rendidos a casa por la tarde? Casi nada.

Todos esos episodios que componen la vida diaria no se metabolizan en experiencias. No ocurría lo mismo en sociedades arcaicas - la de nuestros padres, sin ir más lejos- en las que la vida diaria se alimentaba de lo que cada cual vivía, que era contado en familia, que circulaba entre el pueblo y que, de esa manera, pasaba a formar parte de la vida colectiva. De esos relatos metabolizados socialmente salían máximas, proverbios o refranes que era como el condensado sapiencial de la vida común. Hoy, en lugar de sabiduría común lo que manda son los eslóganes fabricados industrialmente.

Lo que estoy queriendo decir es que el hombre moderno ha perdido la relación con la realidad. Nos pasa a todos lo mismo que a los turistas japoneses visitando El Escorial o NôtreDâme de París: sólo lo ven pegados a la cámara de fotos. Casi nadie mira directamente a las vidrieras o a las piedras. Lo ven a través de un cristal que, para mayor inri, llamamos "objetivo".

Para señalar la diferencia entre nuestra situación y la de nuestros padres he caracterizado la sociedad de éstos de "arcaica". Es una manera de decir que la pérdida de experiencia es definitiva, como definitiva es la desaparición de esa sociedad. No hay lugar pues para la nostalgia. La solución al problema de la pérdida de experiencia no puede pasar por la restauración de una sociedad que ya se fue, sino por la conciencia de que hemos perdido la experiencia. 
b) Para entender bien esta pérdida, manifestada en los comportamientos más cotidianos, quizá convenga analizar casos más extremos, casos en los que se pone de manifiesto la gravedad y lo absurdo de la susodicha pérdida.

El siglo Xx ha sido, decía Hannah Arendt, el más violento de la historia de la humanidad. Hemos tenido que inventar términos nuevos para calificar las modernas ediciones de la barbarie, tales como "crimen contra la humanidad" o "genocidio". Genocidios los ha habido contra los armenios, en los años diez; contra los ucranianos, en los años treintas, luego, en Camboya, en la ex Yugoslavia, en la África de los grandes lagos...

De entre todos los episodios violentos, ninguno comparable al del campo de concentración. Podemos pensar ya sea en los campos nazis o en los campos de estupro étnico de los serbios. En los primeros se mataba sistemáticamente a los judíos por ser judíos, en los segundos se atentaba a la identidad de un pueblo violando y embarazando a las mujeres bosnias para que sus hijos ya no fueran musulmanes.

¿Qué hemos aprendido, qué lecciones hemos sacado de esa experiencia extrema de atentado a la humanidad, de atentado, por tanto, a nuestra propia humanidad? Primo Levi, un superviviente del campo de Auschwitz, que se hace la misma pregunta, dirigida a los propios supervivientes, reconoce que no salieron del campo "ni más sabios, ni más profundos, ni mejores, más humanos o más benevolentes en relación con el hombre". ${ }^{4}$ Es decir, salieron vacíos, desorientados, sin poder transformar la vivencia en experiencia. Muchos de ellos, además, mudos; se negaban a hablar o recordar para poder vivir, tal es el caso de Semprún en La escritura o la vida; otros callaban porque pensaron que nadie creería aquella desmesura; hubo quien, como el propio Levi, no paraba de hablar hasta que se dio cuenta de que sus relatos no interesaban a nadie, ni siquiera a los editores. Y decidió callar durante trece años.

c) Esa incapacidad de los propios supervivientes tiene una explicación que puede ayudar a comprender la misma incapacidad en situaciones menos extremas.

El hombre del campo de concentración no podía hacer experiencias porque había sido reducido a puro cuerpo biológico. En el campo desaparecen los derechos, el nombre, la dignidad, la biografía. El hombre es reducido a puro cuerpo que es designado no con un nombre sino con un número, marcado a fuego, como en los animales. No olvidemos que el campo es el lugar por excelencia del estado de excepción, pues allí todos los derechos del hombre, como sujeto humano y cívico, quedan suspendidos. Sólo en un cuerpo, un número.

${ }^{4}$ Una idea que repite Primo Levi, Hundidos y salvados. Barcelona, Muchnik Editores, 1989. 
Esta reducción a mero cuerpo, esta suspensión del derecho en el campo, es del mayor interés político. ¿Por qué?, porque se elimina esa conquista de la humanidad que llamamos política. En el campo (entiéndase: el campo de concentración), en efecto, se hace público lo privado y privado lo público. Y esa confusión significa la muerte de la política. Veamos. Lo único público del campo es el cuerpo de los prisioneros. Para los nazis, en efecto, lo que les interesaba del judío era su cuerpo. El campo, como lugar público o político, estaba organizado en función del cuerpo: los cuerpos frágiles eran inmediatamente destruidos; los cuerpos hábiles para el trabajo eran utilizados no sólo para la producción sino, sobre todo, para que el propietario de dicho cuerpo interiorizara la no pertenencia a la especie humana; así hasta que, llegados al último grado de deterioro físico y psíquico, eran exterminados en el horno crematorio. El sentido del campo era el cuerpo: reducción del hombre a puro cuerpo y destrucción final del cuerpo.

Ahora bien, si lo más privado se hace público, entonces desaparece toda forma de privacidad, pues lo público es lo privado. ¿Esto, adónde nos lleva? A la negación de la política. Si no hay distinción entre público y privado, si no hay privado, no hay público, pues lo público o político surge del espacio que surge entre la privacidad de cada cual. Eso es lo que queremos decir cuando afirmamos que lo público es el resultado de la libre iniciativa de los particulares; lo política es el resultado de la libertad que surge de lo íntimo o privado de cada individuo. Recordemos, en efecto, que desde los griegos la posibilidad de la política va unida a la distinción entre polis y oikos, entre bios y zoé. Zoé y oikos designan ese momento prepolítico (la casa, el cuerpo), que se distingue del momento político (polis, bios), momento que tiene lugar cuando se abandona el hogar y se plantea no la supervivencia física sino la convivencia. Lo público o político es la proyección de la libertad individual, que es originariamente privada; sin esa privaticidad no hay vida pública en libertad.

El genio de Kafka reside en haber captado esta singularidad moderna. No sólo es genial por su denuncia de la burocratización de la vida sino también por haber visto la disolución de la distinción entre público y privado. Recordemos que El Proceso comienza con la sorpresa de que la sala contigua a su dormitorio se ha convertido en un tribunal y que cuando $\mathrm{K}$ pide a la sirvienta el desayuno quien aparece es un oficial del juzgado con una orden de detención.

Resumiendo este punto: en el campo se borran las diferencias entre público y privado porque se confunde el cuerpo político con el cuerpo biológico. Entonces la política queda reducida a lo privado. La política es oiconomía. El espacio público, lugar de la libertad y de la interacción, queda reducido al cuerpo. La política decide sobre la seguridad o inseguridad, sobre el mantenimiento o destrucción del cuerpo. 
Lo que conviene tener bien claro es que a esa crisis epocal -a la pérdida de experiencia- no se puede responder pretendiendo restaurar la experiencia por las siguientes razones: en primer lugar, porque no lo tolera la modernidad. Al desaparecer el espacio público y ser tratado el hombre como nuda vida, como ser biológico, el hombre real queda aislado frente al poder, es decir, el poder no lo considera como un sujeto político sino como objeto de la política. La consecuencia inmediata de este poder es neutralizar toda iniciativa, toda libertad o autonomía del sujeto. Esta preocupación es la que subyace a la teoría de la "movilización general" de Jünger, teoría perfectamente descriptiva del fascismo y quizá no sólo del fascismo. Según esta teoría, el poder aparece como una necesidad o exigencia de fuerzas superiores, tantos las de la naturaleza como las de la historia, que envuelven y arrastran la voluntad del individuo (no es por casualidad que el fascismo gusta tanto del término "movimiento"). El "respeto" a esa lógica impuesta obliga al poder a neutralizar todo ejercicio de libertad del individuo. A la fuerza determinante del "movimiento general" nada se opone tanto como la pretensión de la libertad individual de tener un proyecto propio. Eso es visto como un atentado a la lógica implacable de la naturaleza o de la historia que son las que animan la dinámica del "movimiento general".

Walter Benjamin explicaba esta situación recurriendo al mito de la expulsión del paraíso: el sentido de la caída sería la sustitución del lenguaje por el juicio. ${ }^{5}$ El lenguaje adámico es expresión de lo que son las cosas; es escucha y expresión de lo recibido. El lenguaje postadámico es juicio o decisión en el sentido de que quiere sustituir esa modesta función del nombrar, una vez escuchada la realidad, por la función divina de imponer el nombre. El juicio imita malamente al lenguaje divino, que es creador, pretendiendo que las cosas sean lo que el nombrador decide que sean. En este caso, el hombre, que se toma por Dios, queda fuera de la realidad, confundiendo su juego de palabras con la realidad misma.

La pérdida de experiencia es como la expulsión del lenguaje, es decir, la utilización de la comunicación no en función de la capacidad y necesidad comunicativa del hombre, sino en función de los intereses de la propia comunicación. No es lo mismo una comunicación en función de la comunicabilidad del hombre que una comunicación al servicio de los intereses propios de la comunicación. Hay un caso particularmente ilustrativo de esta transformación tan típica de nuestro tiempo, tan típica que bien pudiéramos llamar al

5 W. Benjamin, "Sobre el lenguaje en general y sobre el lenguaje de los hombres", en Sobre el programa de la filosofía futura y otros ensayos. Caracas, Monte Ávila, 1970 , pp. 139-155. 
poder moderno, al Estado contemporáneo, no un Estado-nación sino un Estado-espectáculo. Me refiero a una célebre emisión de televisión, emitida desde Timisoara (Rumania) que conmocionó al mundo. Ante los ojos del espectador se producen unas escenas de tortura y muerte de los Ceauscescu, símbolos y protagonistas de una legendaria dictadura comunista, por unos salvadores de la patria que de esta guisa buscan legitimidad en el ejercicio de su nuevo poder. Luego supimos que todo aquello fue un montaje. No hubo en realidad ante las cámaras de televisión tortura y muerte, ya que los Ceauscescu estaban muertos, pero el espectador lo captó como verdadero, pues ante el espectador desaparece la distinción entre verdad y simulación. Lo de menos es si la escena es verdad o mentira, pues se confunden: lo importante es que el espectador lo capte como verdadero. Eso es lo que vale.

Si la dinámica política moderna está dominada por el principio de la "movilización general", por un lado, y por el principio "espectral" de la fusión o confusión entre realidad e imagen, la reivindicación de la experiencia del sufrimiento como principio generador de los contenidos políticos queda literalmente fuera de la realidad.

3. No decimos, empero, toda la verdad cuando describimos los tiempos que corren como "tiempos de despolitización" en el sentido de que falta el subsuelo de lo político (la experiencia) que haría posible esa política que extrañamos.

Hay que dar un paso hacia atrás y reconocer que, pese a esa crítica de despolitización, sí hay política. De alguna manera, todo es política. Nada escapa, por un lado, al panóptico del Estado y, por otro, toda realidad existente quiere convertirse en Estado, aunque empiece hablando de nación o nacionalidad. El auge de los nacionalismos denota la vigencia o virulencia de la política, en el sentido de que la figura estelar de la política es el Estado y no hay comunidad o pueblo que se precie que no quiera acabar siendo Estado. La política, en ese sentido, nos invade.

a) ¿Qué es lo que caracteriza a la política existente? Es la pregunta del millón. Ingentes masas de libros, artículos, pensadores y escritores se abalanzan sobre esa pregunta. Para dar idea del barullo recordemos que para su abordaje hay una nutrida variedad de "áreas de conocimiento" que pujan por el lugar correcto. Están, en efecto, la filosofía política, la teoría política, la ciencia política...

Yo me atengo a un tipo de filosofía o teoría -lo de ciencia me parece excesivo- política que tiene la virtud de ser constante a lo largo de los últimos siglos, aunque me centre en la formulación que de esa forma de ver la política da Carl Schmitt. Llama la atención el hecho de que pese a los merecidos y contundentes juicios condenatorios que se han vertido sobre este pro- 
vocador pensador "filonazi", las tesis de Schmitt sigan fascinando hasta a la misma extrema izquierda. ${ }^{6}$

Pues bien, "la diferencia específica de la política", dice Schmitt, "a la cual pueden remitirse los actos y los móviles políticos, es la discriminación entre amigo y enemigo". ${ }^{7}$ Schmitt habla de "distinción específica" para dar a entender que lo político es la diferencia específica de un género llamado cultura. La cultura abarca a la totalidad del pensar y del actuar humano, pero sin perder de vista que ese pensar y ese actuar operan sobre algo previo que es "cultivado" por el hombre. Lo cultivado es la naturaleza y se le puede cultivar para someterse a ella o para someterla, pero el fundamento de la cultura, lo que subyace a ella y sirve como de materia prima, es el status naturalis. Pues bien, el status naturalis, para Schmitt como para Hobbes, es el de la "guerra de todos contra todos". Eso es lo originario para la política o, como prefiere decir Schmitt, "lo originario políticamente". Es verdad que hay una diferencia entre ambos, pues mientras que para el británico la beligerancia natural tiene una connotación individualista, para el alemán la guerra es de pueblo contra pueblo. De más graves consecuencias es, sin embargo, otra divergencia entre ellos. Mientras que para Hobbes hay que abandonar lo político originario, reconvirtiendo la política en defensa de la vida, para Schmitt eso sería tanto como negarse a ser hombre. La política tiene que seguir siendo fiel al espíritu originario, de ahí que la entienda como disponibilidad a la muerte. En Hobbes, pues, la política es la negación de lo político, mientras que, para Schmitt, es su reforzamiento. Pero si bien nos fijamos, uno y otro ponen el acento en el cuerpo, pues ¿qué se quiere decir cuando se habla, en un caso, de la "garantía de la vida" y, de otro, en "disposición al sacrificio de la propia vida", como definición de la política? En ambos casos lo que importa es la vida, pues aunque haya que sacrificarse por ella, es por ella que uno se sacrifica.

Si el sujeto de la política moderna es el cuerpo, hay que señalar inmediatamente que los cuerpos están en una relación de enfrentamiento. En esta definición dos veces usa Schmitt la misma palabra que se suele traducir por "diferencia" o por "discriminación”. El original utiliza la expresión Unterscheidung que es una palabra más fuerte que las dos empleadas en la traducción. Lo que

${ }^{6}$ Carl Schmitt, Der Begriff des Politischen. Berlín, Duncker u. Humbolt, 1963; Jürgen Habermas, "Vuelve Schmitt. De legitimador del nazismo a inspirador de la posmodernidad", en Supl. de libros de $E l$ País, 6 de noviembre de 1986; Leo Strauss "Observations sur le concept du politique de Carl Schmitt", en L. Strauss, Le testament de Spinoza. París, Cerf, 1991, pp. 313-337; Jacques Derrida, Politiques de l'Amitié. París, Galilée, 1994, pp. 104-128.

7 C. Schmitt, "El concepto de lo político", en Estudios políticos. Madrid, Doncel, pp. 87 y ss. 
se quiere decir con ella es que la diferencia en cuestión discrimina y divide. La diferencia entre pueblos, que es lo que sería la política originariamente, hay que entenderla como una oposición que desemboca en el enfrentamiento y, a la postre, en la guerra.

Esto queda más claro si analizamos qué entiende Schmitt por enemigo: "es una comunidad de hombres que, de acuerdo con las posibilidades reales, puede eventualmente convertirse en una comunidad beligerante frente a otra comunidad”. El enemigo es un concepto público, no privado, que lleva en sí la posibilidad de la guerra. Desde el momento en que la guerra es eventualmente posible, el enemigo acompaña como una sombra a la propia comunidad que, de este modo, se constituye como una comunidad humana de combate.

Para evitar la tentación de entender al enemigo en un sentido psicologista, Schmitt recomienda traducir su Feind (enemigo) por hostis y no por inimicus. Y es que mientras hostis se traduce por aquel con el que tenemos un enfrentamiento público, inimicus queda restringido al campo privado de los odios. El inimicus nos odia; el hostis se nos enfrenta. Una vez delimitado el campo propio -el público- del enemigo, quedan por precisar los sujetos de los enfrentamientos. Schmitt recurre a Platón para quien sólo una guerra entre griegos y bárbaros es verdadera guerra, mientras que las luchas entre griegos son del orden de las querellas intestinas. La idea dominante aquí es que un pueblo no puede hacerse la guerra a sí mismo y que una guerra civil es sólo un desgarro interior pero no apunta hacia la conservación o formación de un Estado distinto. Así que resulta que el hostis o polemos, para el griego, es el bárbaro; mientras que el inimicus o ekhtros puede ser de casa. Con el primero hay guerra total (que pone en juego el ser o no ser del pueblo), con el segundo, "sólo" guerra civil.

¿Qué se desprende de este planeamiento? Pues que el enemigo es el otro pueblo, por el mero hecho de ser otro pueblo, y, por consiguiente, el amigo es el propio pueblo. El enemigo es el extranjero, el de otra raza. La comunidad de uno se constituye por la raza, por el parentesco. La política sería, por consiguiente, una forma de cultura o cultivo de la naturaleza, en el sentido más literal de la palabra: fidelidad a la sangre y negación de la otra sangre. Lo que da solidez a la comunidad, más allá del discurso, es la sangre, los lazos del nacimiento. Cuando la política pierda de vista esta relación agónica con los otros pueblos, sustituyendo la disposición a ir a la guerra por desarrollos económicos o por principios morales, se habrá perdido la sustancia de la política, dirá Schmitt. Valores como la verdad, la libertad o la igualdad que abstraigan de esta fidelidad a la propia sangre serán caricaturas de sí mismos. Ser libre es poder seguir la tradición, es decir, ser fiel -y fiel continuador- a nuestros padres, a nuestros muertos. 
¿Qué se deduce de todo esto? Pues que la política se basa en el parentesco real o en los lazos de nacimiento. ${ }^{8}$ La política moderna añade un elemento a la sangre: la tierra, el territorio. El Estado es un territorio formado por los que nacen ahí. La política moderna es impensable sin esta tríada: Estado, nacimiento, territorio. Esa tríada ha sustituido a Dios en asuntos de principio legitimador de la política.

Aunque esa descripción invita a concebir al Estado en forma de tribu, tengamos en cuenta que Hegel lo llama "totalidad ética", dando a entender un aspecto excelso de esa figura política. Hegel eleva el Estado a la categoría de "totalidad ética", ${ }^{9}$ un enorme halago filosófico, pues, por primera vez, la humanidad encuentra una figura en la que se concilia "la libertad subjetiva con la universalidad objetiva”, es decir, se concilian los intereses del individuo

${ }^{8}$ A Derrida lo que le llama la atención, analizando la teoría de Schmitt, es que hoy todos, independientemente de que uno sea schmittiano o no, damos por bueno ese fundamento. Y lo hacemos curiosamente en el momento en que más espirituales nos ponemos, por ejemplo, cuando hablamos de fraternidad o de igualdad. ¿En qué basamos esos valores universales, revolucionarios? En el nacimiento, en la consangüineidad. Hermanos e iguales somos por nacimiento, por haber nacido en el mismo territorio o por haber nacido hombres. La racionalidad vendrá aquí a reconocer la comunidad de la sangre.

Si los cimientos de la política se basan en la naturaleza, cabe preguntarse, como hace Derrida, qué papel juegan elementos no-naturales tales como la virtud y la sabiduría. Tienen su importancia en la vida social pero no en la fundamentación de la política, por eso Derrida puede cuestionar un tipo de democracia, la nuestra, en la que sus piedras angulares - los conceptos de Estado o ciudadano- sean de origen natural y no producto de la virtud o del saber (J. Derrida, op. cit., p. 127).

Pudiera parecer que la democracia liberal moderna está lejos de Hobbes y, más lejos, aún de Schmitt. Lo que es innegable es que estamos dentro de una tradición política europea que viene de lejos, marcada toda ella por la comprensión de lo político como la "distinción amigo-enemigo". A ella pertenece también la teoría del Estado de Hegel.

${ }^{9}$ Claro que esa grandiosa figura tiene un pero, pues la totalidad ética del Estado es una totalidad en minúscula. No se puede cerrar los ojos, en efecto, a la evidencia de que junto a un Estado hay otro y otros muchos. La relación entre ellos no es de eticidad alguna sino de pura enemistad, de rivalidad, de conflicto o, como ahora se dice, de competitividad. "En la relación de los Estados", dice Hegel en su Filosofía del derecho "...entra el juego sumamente animado de la particularidad interna de las pasiones, intereses, finalidades, de los talentos y virtudes, de la violencia, de la injusticia y del vicio". Por eso, si se quiere hablar de "totalidad ética" con mayor rigor habría que pensar en una figura superior al Estado, que no será una federación de Estados, sino "la historia universal como tribunal del mundo". Allí donde los Estados pueden resolver racionalmente sus conflictos y reconciliarse en la sede de la historia universal. Lo importante de esta reflexión no es la utopía de un gobierno mundial, sino la imposibilidad de que dos Estados se reconcilien, pues, por definición, se tienen declarada la guerra, como si sólo pudieran constituirse en pueblo, negando al otro pueblo. 
con los de la colectividad. Eso significa que, de puertas adentro, los miembros del Estado están obligados a la solidaridad, pues lo que ahí pasa es cosa de su libre voluntad. Si nos preguntamos por qué, ante una catástrofe en Andalucía, por ejemplo, el Estado español tiene que hacerse cargo de los problemas que puedan surgir y responder en justicia, y ante una catástrofe en Marruecos, que sólo está a dieciocho kilómetros, el Estado español se siente satisfecho con algún gesto de caridad, la explicación hay que buscarla en esa idea del Estado como "totalidad ética": lo que ocurre dentro de él nos incumbe porque de alguna manera lo que ahí suceda depende de nuestra voluntad; lo que ocurra en otro Estado ya no nos incumbe, pues la ética política es de fronteras para adentro. Con los de fuera es asunto de otro negociado, el de la caridad. Notemos que si el Estado es una "totalidad ética", no hay criterios morales superiores al Estado. Gracias a ese título, el Estado segrega necesariamente una especie de "nacionalismo ético": lo bueno se identifica con lo que conviene al propio pueblo, a la propia etnia, que es la encarnación del concepto de amigo. ${ }^{10}$

b) Si esto es así, reflexionemos sobre las consecuencias que de ello se derivan para aquellas teorías universales morales, tales como los derechos humanos, que se fundamentan en elementos extraños a la tríada Estado-nacimiento-territorio.

Me permito decir que para la política moderna, pese a toda la fanfarria retórica dominante, los famosos derechos humanos son inaceptables, incomprensibles porque no hay más derecho que el que se funda en y que reconoce el Estado. Si el hombre tuviera algún tipo de derecho por la sencilla razón de ser hombre, lo tendría sin que el Estado tuviera nada que objetar. Pero, como bien decía aquel ministro español de Asuntos Exteriores, Abel Matutes, a propósito del Ejido, "para el Estado el inmigrante sin papeles, no existe". ${ }^{11}$ Coincide con lo que decía Hannah Arendt, a la vista de aquellos millones de seres que antes, durante y después de la Segunda Guerra Mundial, deambulaban sin sentido buscando una patria de acogida: quien se presentara ante cualquier gobierno sin papeles estaba perdido, pues "el mundo no halló nada sagrado bajo la abstracta desnudez del ser humano". ${ }^{12}$ Para el mundo, para los políticos, para el Estado, la dignidad humana, sin papeles, no vale nada.

${ }^{10}$ Lo que quiero decir es que el ataque a la necesaria universalidad de la moral no se da sólo en el nacionalismo étnico (vasco, por ejemplo) sino también en el nacionalismo del Estado (españolismo). La única diferencia es que el Estado puede constar de dos o más etnias, mientras que los nacionalismos se quedan en una. Pero las etnias de un Estado son las que son y no son las que vienen de fuera.

${ }^{11}$ Véase mi artículo "El campo del moro", en El Periódico de Catalunya, núm. 12, febrero, 2000.

${ }^{12}$ Hannah Arendt, Los orígenes del totalitarismo III, p. 434. 
No son boutades sino la interpretación políticamente correcta de la Declaración de los Derechos del Hombre y del Ciudadano de 1789. Cabían dos interpretaciones: que sólo tienen derechos humanos los que son ciudadanos (es la políticamente correcta) o que se tienen derechos ciudadanos por el hecho de ser hombres (la que los Estados no quieren ni ver). No hay nada que ponga más en evidencia las desnudeces del Estado que el indocumentado, por eso habría que considerarlo como la figura política que más da que pensar en nuestro tiempo. El indocumentado -ya sea inmigrante ilegal, apátrida, refugiado o exiliado- pone al descubierto la falacia de la figura del ciudadano. La ciudadanía, en efecto, no se basa en ninguna dignidad ínsita al ser humano por el hecho de nacer humano, sino que es un reconocimiento del Estado, un acto del imperium, es decir, nos revela quién decide sobre los derechos humanos: el poder.

Estado e indocumentado se repugnan, por eso los Estados inventaron el campo de concentración, para situar en un no-territorio a gentes sin derechos. ${ }^{13}$ Los campos de concentración no fueron una idea de los nazis sino la solución que los Estados inventaron para resolver el problema de las gentes sin papeles. No parece que desde entonces se haya inventado nada mejor.

El indocumentado no sólo supone un quebradero de cabeza para las políticas de empleo o de escolaridad o de salud de los Estados de bienestar, como estamos viendo cada día, sino que representa el mayor problema político del futuro y, desde luego, el mayor desafío a la figura política del Estado. ${ }^{14}$

c) Acabo de mencionar el campo de concentración y quisiera detenerme un instante en él, no para hablar de los judíos (ellos estaban internados fundamentalmente en campos de exterminio) sino de nosotros mismos.

¿Qué es un campo de concentración? Un lugar en el que se ha suspendido el derecho, los derechos, es decir, es el lugar del estado de excepción. Cada vez se habla más, en filosofía política, del campo como símbolo de la política moderna. Es una tesis muy osada, pues parece que queremos comparar a la democracia liberal con el fascismo. Eso sería una exageración y, desde luego, un insulto para las víctimas de los campos. Ya hubieran desea-

${ }^{13}$ Joaquín Xirau ofrece un testimonio revelador. Cuenta que acompañó a Antonio Machado y a su anciana madre en su salida de España, cuando las tropas franquistas entraron en Barcelona. Fue un viaje a pie, lleno de calamidades. Cuando llegaban a la frontera francesa con lo puesto y sin papeles quedaban a merced de la policía francesa "que recogía a los españoles indocumentados para llevarlos a un campo de concentración”. El grupo de Xirau y Machado se salvó porque aquél llevaba un papel salvador: una invitación de la Sorbona para dar una conferencia. Cf. J. Xirau, Obras completas I. Barcelona, Anthropos, 1998, pp. LIX y LX.

${ }^{14} C f$. G. Agamben, "Política del exilio", en H. C. S. Gorski, Identidades comunitarias y democracia. Madrid, Trotta, 2000, pp. 82-92. 
do para sí las reglas de juego, incluso las más mezquinas, de la democracia liberal.

Y, sin embargo, no conviene desechar tan rápidamente esa osada tesis, pues lo que se quiere decir no es que las reglas de juego explícitas sean iguales, sino que hay una serie de supuestos implícitos cuya presencia explicaría por qué es tan corto y tan cómplice el espacio que media entre el fascismo y el liberalismo. El sociólogo Zygmond Baumann suele decir que lo grave del holocausto no es que sucediera una vez, sino que cualquiera de nosotros puede convertirse en verdugo. Enumeremos algunos de esos supuestos que nos habitan:

- El liberalismo, ¿es una apuesta por la libertad o por la seguridad del cuerpo y de los bienes? Según Foucault, ${ }^{15}$ el liberalismo usa de la libertad como combustible de un sistema en el que lo importante es el equilibrio entre libertad y seguridad. Lo que el liberalismo hobbesiano pretende es garantizar la seguridad de personas y bienes.

Hoy se presenta al liberalismo como la antítesis del fascismo. Es una tesis apresurada. Recordemos que: el fascismo convivió con el liberalismo económico; que el fascismo sedujo inicialmente a muchos liberales; que el liberalismo cayó como un castillo de naipes ante el primer envite del fascismo, de ahí el prestigio del comunismo entre los intelectuales progresistas pues era el único capaz de frenar la barbarie fascista, por no citar la tesis de Marcuse que habla de la profunda complicidad entre liberalismo y fascismo. ${ }^{16}$

- La relación entre progreso y barbarie. A primera vista son antagónicos, pero quizá sean cara y cruz de la misma moneda. Tienen algo en común: el progreso acepta el costo humano como precio del bienestar de futuras generaciones; la barbarie es la reducción del hombre a nuda vida. "No hay un solo documento de cultura que no lo sea también de barbarie", ${ }^{17}$ dice Benjamin. No quiere decir que sean lo mismo sino que no sabemos avanzar más que sobre las espaldas de los vencidos.

- La parcialidad de las lecturas de la historia. De lo dicho anteriormente se desprende que hay dos lecturas muy diferentes de la misma historia: lo que para el vencedor es progreso, para el vencido es barbarie; los costos históricos, que para el vencedor son una anomalía provisional,

${ }^{15}$ Curso de Foucault en Le Collège de France, 1983.

${ }^{16}$ Para seguir los vaivenes del liberalismo en el siglo xx, véase Enzo Traverso, Le totalitarisme. París, Seuil, 2001.

${ }^{17}$ Lo dice en la tesis séptima de su escrito "Sobre el concepto de historia", en W. Benjamin, Discursos interrumpidos. Madrid, Taurus, 1973, p. 182. 
una excepcionalidad, son, para los vencidos, la regla. ${ }^{18}$ Esto significa que la misma historia admite dos lecturas: lo que, desde el punto de vista de los vencedores es progreso, es, para los vencidos, opresión. Para ellos el estado de excepción -con lo que esto conlleva- es la regla.

Esta doble visión de la misma realidad es de la mayor importancia pues pudiera ser que las construcciones más bellas, más universalistas de nuestra cultura, fueran de hecho las interpretaciones particulares de los vencedores. Los únicos que no caerían en esa ilusión serían los oprimidos: ellos saben por experiencia que siempre son los paganos de esa particularísima universalidad. Lo preocupante es que sólo conocemos propuestas de reconciliación de los dos puntos de vista, hechas por una parte. Me refiero a las filosofías modernas de la historia, que son ideología de Occidente. Su demostrada parcialidad deja abierta la puerta de una universalidad que no sea excluyente.

- Una vez reconocido que fascismo y liberalismo son, desde el punto historiográfico, radicalmente diferentes, lo que hay que preguntarse es cómo es visto el hombre concreto, el ciudadano, en uno y otro caso. Hoy lamentamos la reducción del ciudadano a cliente, del trabajador a consumidor (sic Habermas). Es una tendencia cuyo final quizá apuntaba Kafka cuando analizaba al hombre. Kafka recurría con frecuencia a la metamorfosis del hombre en bicho. ${ }^{19}$ Era una forma de señalar esa evolución del bios a zoe, de la política en biopolítica, es decir, era una forma de señalar la entraña no-humana de la política que conocemos.

\section{La justicia}

1. ¿Por qué hablar aquí de justicia? Porque es la sustancia de la política. Al menos hay una tradición de filosofía política para la que política equivale a justicia. Para Aristóteles ${ }^{20}$ la política es la manera de resolver un conflicto fundamental de la sociedad: el enfrentamiento entre pobres y ricos. Porque resulta que pobres y ricos "son los dos partidos de que se compone la sociedad" (1318a) y la política consiste en hacerles convivir, una ardua tarea, pues "los débiles siempre buscan la igualdad y la justicia, mientras que los más poderosos no se preocupan en absoluto de ella" (1318b). Mas no se puede

18 "La tradición de los oprimidos nos enseña que la regla es el estado de excepción en el que vivimos", dice W. Benjamin, tesis octava, idem. p. 182.

${ }^{19}$ La Metamorfosis comienza así: "Una mañana, tras un sueño intranquilo, Gregorio Samsa se despertó convertido en un monstruoso insecto".

${ }^{20}$ Remito a Aristóteles, Política, libro IV, cap. III. 
decir en menos palabras: la política consiste en hacer justicia, pero la justicia sólo parece interesar a quienes padecen la injusticia. Aristóteles no se fía de la idea de justicia que tengan los ricos; prefiere partir de la experiencia de la injusticia. ¿Cómo hacer para que los que crean la injusticia se impliquen en la justicia? Sólo hay dos caminos: o que éstos nos digan cómo entienden la justicia y que quien padece la injusticia lo acepte (que es lo que suele ocurrir) o que lo digan los que sufren la injusticia (que es lo que nunca ocurre). El primer camino tiene el inconveniente de que puede que nunca se enteren en qué consiste la injusticia; y, el segundo, de no llegar nunca una teoría de la justicia. Pero lo que no hay que perder de vista es que la política no se ocupa de una vaga convivencia sino de la existencia justa. Lo dijo Aristóteles y lo repite ahora Rorty, con su habitual franqueza: "las cuestiones políticas centrales giran en torno a las relaciones entre ricos y pobres". ${ }^{21}$

2. La justicia se ha convertido en las últimas décadas en un tema mayor de la filosofía política, lo que debería incitar al optimismo. Ya no es tratada como una mera virtud, como hacían los antiguos; ahora es mucho más: es el fundamento que legitima la política. Como dice Rawls "el objetivo primario de la justicia social es la estructura básica de la sociedad". ${ }^{22}$

No de cualquier sociedad, sino de la sociedad moderna, que es plural. ¿Cómo alcanzar criterios comunes de justicia si cada cual tiene una idea distinta de lo que es bueno y malo? Sólo si esos criterios son racionales, que es tanto como decir universales. Y ¿qué es lo racional en un mundo tan variopinto? No hay que buscar lo racional del lado del contenido, de los sustantivos (que son muy particulares) sino del lado del procedimiento, un procedimiento neutro e imparcial, que dé juego a todo el mundo. Hay que cargar la suerte, pues, sobre el momento deliberativo, sobre el proceso de decisión.

Las justicias modernas son deliberativas o procedimentales. A las teorías de la justicia que priman el procedimiento se les llama liberales, se prohíben "cualquier jerarquización de las diferentes concepciones de la vida buena que se pueda encontrar en la sociedad". ${ }^{23}$ Propio, pues, de las teorías liberales es una concepción neutra e imparcial de la justicia respecto a las distintas concepciones de la vida buena. El pobre, si quiere ser justo, tiene que olvidarse de su pobreza y el rico no tiene que hacerse eco ni de su mala conciencia. Hay que ponerse una venda ante los ojos - el velo de la ignorancia, dice Rawls.

Ahora bien, si los criterios de justicia son la neutralidad y la imparcialidad, estamos reduciendo la justicia a un reparto de la libertad. Decimos, en efecto,

${ }^{21}$ R. Rorty, "Utopías globales, historia, utopía”, en Pensamientos de los confines. Buenos Aires, núm. 1, segundo semestre, 1998, p. 115.

${ }^{22}$ John Rawls, Teoría de la justicia. México, FCE, 1985, p. 75.

23 Philippe van Parijs, ¿Qué es una sociedad justa? Barcelona, Ariel, 1993, p. 197. 
que los criterios de justicia tienen que ser racionales. La racionalidad en un mundo moderno (es decir posmetafísico y plural), consiste en intervenir simétricamente en el proceso de decisión. Es la hora del "discurso". Se trata de salvar la igualdad en la decisión, pues sólo así se salva el sacrosanto principio de autonomía del sujeto. En efecto, si yo tengo que decidir presionado por esto o aquello, no soy libre; y de poco vale mi libertad si resulta que no vale lo mismo que la de los demás a la hora de decidir. Así que lo importante en esto de la justicia es conseguir unos criterios de lo que sea justo o injusto que valgan para todos; para que eso sea posible, tienen que ser decididos por todos en igualdad de condiciones; para decidir en igualdad de condiciones todos tienen que disponer del mismo grado de libertad, todos tienen que estar igualmente liberados de presiones, experiencias, prejuicios. De lo dicho se deduce que la igualdad es fundamental para la justicia, pero esa es una igualdad que no tiene nada que ver con "las desigualdades sociales", sino que se refiere a la libertad. Igualdad en la libertad. Ahí tenemos reducida la justicia a libertad. ${ }^{24}$

3. Pero la justicia no es un asunto de libertad sino de pan. Pan y libertad no son incompatibles, por supuesto. Van juntos. Pero con un orden. Dice Bloch: "el estómago es la primera lamparilla en la que hay que echar aceite" y "el hambre y el amor ponen al mundo en movimiento". Pero en ese orden. Si la justicia se reduce a un problema de libertad, habremos despolitizado la política. Eso explicaría por qué se ha abaratado tanto la democracia. Desde 1989 se han creado veintidós nuevos Estados y todos son democracias liberales. Más aún, lo son no en contra sino con el beneplácito de los países más ricos y poderosos del mundo. Ése es el hecho sorprendente. Hasta hace poco tiempo, los Estados poderosos recelaban de las nuevas democracias (pensemos en la animosidad de Estados Unidos respecto a la democratización en los países pobres, en los años cincuentas y sesentas). Ahora las apoyan a bombo y platillo. Quizá se entienda el cambio de actitud si examinamos lo político de las nuevas democracias liberales y lo comparamos con las antiguas democracias. Durante mucho tiempo, en efecto, la democracia era una exigencia fuerte porque al concepto de libertad en política iba unida la idea de un reparto del patrimonio nacional entre todos los miembros de la sociedad democrática. Decir democracia era reconocer que el Estado no eran unos pocos, sino que a él pertenecía toda la sociedad. Para decirlo breve y pronto: en esas democracias la idea de libertad iba unida a la de justicia. Las nuevas democracias libe-

${ }^{24} \mathrm{~S}$. Nino lo señala oportunamente cuando al resumir a estas teorías liberales dice que "la justicia consiste en una distribución igualitaria de la libertad"; véase "Justicia", en E. Garzón Valdés y F. J. Laporta, eds., El derecho y la justicia. Madrid, Eiaf/Trotta, 1996 , p. 478. 
rales ya no tienen ese problema desde el momento en que hasta la justicia es un asunto de libertad. "El mundo tendrá hoy, como agudamente decía Mayor Zaragoza siendo director de la Unesco, más libertad pero menos democracia”.

4. En la medida en que nos interese la política material hay que reivindicar la justicia con contenidos materiales. En la reflexión sobre la política hemos dejado al hombre reducido a puro cuerpo, animalizado. Pues bien, la respuesta a esa situación o amenaza es la "existencia justa", la justicia en la existencia. ¿Qué podemos entender por justicia?

a) En primer lugar, algo que no tiene que ver con derecho. El derecho no es justicia. El derecho es violencia porque es impositivo, coactivo, único. Eso le lleva a una insuficiencia moral, por eso distinguimos casi instintivamente entre legalidad y legitimidad. Una decisión puede ser todo lo legal del mundo y sin embargo ser inmoral. La legitimidad requiere un plus, un plus moral.

No olvidemos, además, que el derecho no tiene por objetivo hacer justicia sino decidir. Lo importante es acabar con un conflicto dictando sentencia. Roma locuta causa finita. Lo importante es que el juego siga. Eso lo saben muy bien los jugadores de futbol ingleses que no discuten las decisiones arbitrales: saben que para que el juego pueda seguir hace falta tomar una decisión y acatarla. La sentencia no tiene que ser justa; tiene que ser válida y la validez no la da la verdad sino el respeto al procedimiento. No hay que buscar pues la justicia primordialmente del lado del derecho, de las leyes, del Parlamento, del Estado.

b) La justicia es el reconocimiento del valor absoluto del singular. Por ahí empieza la justicia. Eso significa, en primer lugar, que nadie es carne de cañón, ni costo del progreso, ni cobaya de experimentación. Se afirma el valor absoluto de la vida individual. Por eso justicia se opone a toda filosofía progresista de la historia (la que coloca al progreso como objetivo de la humanidad) y también a toda teoría abstracta de justicia (la que pide que ignoremos la propia experiencia de injusticia).

Toda teoría moral que declare in-sensata, es decir, carente de sentido, la experiencia concreta, es perversa. Esta crítica es aplicable a los derechos humanos que nos hablan de que todo hombre, independientemente de su color o condición, es igual al otro hombre porque todos tenemos la misma dignidad. Es un planteamiento ideológico, pese a su buena intención, porque habida cuenta de que no somos iguales de hecho, sólo podemos decir que lo somos si frivolizamos la situación de hecho. Los derechos humanos crean buena conciencia cuando lo que tendrían que crear es indignación. No debemos hablar de derechos humanos porque la palabra derecho connota un reconocimiento legal (por el hecho de ser hombres) que no se da nunca; habría que hablar de una exigencia moral a la igualdad, etcétera, pero partiendo de la desigualdad real. 
Y no es, desde luego, poca cosa porque si partimos de la experiencia de la injusticia, a la hora de hacer una teoría de la justicia, lo que queremos decir es que la justicia ni hay que importarla del mundo ideal, ni hay que transportarla a la abstracta construcción de una "comunidad ideal de diálogo". La justicia es respuesta material a la experiencia de injusticia.

c) La afirmación del valor absoluto del singular lleva consigo otra grave consecuencia: la actualidad o vigencia de las injusticias cometidas en el pasado y que no han sido saldadas.

Para la justicia las injusticias no prescriben por mucho tiempo que haya pasado ni porque el deudor se declare incompetente. No prescriben las injusticias cometidas contra o por nuestros abuelos por dos razones. Imaginemos, en primer lugar, que el crimen prescriba porque han pasado unos años, ¿qué impide entonces que el crimen se repita? Si prescribe el crimen es porque hay que facilitar la vida de los vivos, pero si sólo importa la vida de los vivos ¿por qué va a parar el criminal de matar si lo que importa es negociar con los vivos que queden? ${ }^{25}$

La segunda razón es la aparición de la memoria en política. Si la política sólo tuviera que lidiar con el derecho, podía permitirse el lujo de cancelar el pasado, creando la figura de la prescripción. Pero resulta que en política, como en cualquier otra actividad humana, también interviene la memoria y ésta abre lo que el derecho cancela. La memoria da a la política un inevitable tono de duelo.

La memoria es un componente fundamental de la justicia. Ésta es una vieja convicción que no por olvidada es menos cierta. El peso de la memoria está presente en los mitos fundacionales de la moderna política. Recordemos cómo Rousseau y Kant reelaboran el mito del paraíso, de la expulsión del paraíso: la humanidad vivió una etapa de su vida en la inocencia y el bienestar natural; de esa fase se sale cuando el hombre hace uso de su libertad e inteligencia. Es la caída. ¿Qué quieren decirnos? Que este mundo nuestro lleno de conflictos y desigualdades es producto de nuestra libertad y que tenemos que asumir esa responsabilidad. ¿Cómo? A través del contrato social que debería intentar, desde la libertad, reconstruir modestamente la convivencia que una vez tuvieron como don de la naturaleza. La memoria nos obliga a hacernos responsables de las desigualdades existentes porque son cosas del hombre, de nuestros abuelos, que nosotros heredamos. Si las desigualdades son injusticias porque han sido causadas por el hombre y nosotros las hemos heredado, no

25 Esa lógica la entienden bien los terroristas que les da lo mismo matar dos que doscientos porque saben que, a la hora de negociar, lo decisivo es la vida de los vivos. Y éstos están dispuestos a pagar cualquier precio - ofreciendo la amnistía y el perdóna cambio de la seguridad de la vida de los vivos. 
basta con crear un orden social racional y libre. Hay además un problema de injusticias respecto al pasado.

¿Qué se deduce de todo ello? Que si las desigualdades actuales son injusticias, entonces el tiempo forma parte de la política y también el espacio. No sólo es justo que Pinochet tenga que rendir cuentas fuera de Chile (universalidad espacial) sino que cualquier juez puede exigir a un contemporáneo responsabilidad por injusticias pasadas y heredadas (universalidad temporal). Realmente, lo que se opone a memoria no es olvido sino injusticia.

\section{Educación}

¿Y qué tiene que ver la política y la justicia con la educación?, ¿es acaso la guinda de la tarta o es una pieza clave de la política tal y como aquí ha quedado insinuada, es decir, como "existencia justa"?

Los especialistas en educación saben perfectamente que la educación está al servicio de valores sociales que no define la propia actividad educativa sino que los presupone. Mientras preparaba estas notas he tenido que revisar las Obras completas de Joaquín Xirau, un gran filósofo catalán, muerto en el exilio. Como buen institucionista, amigo y discípulo de Bartolomé del Cossío, buena parte de su obra está dedicada a la educación, a definir los fines de la educación. Este asunto, que ocupa el segundo volumen, es incomprensible sin el primero, en el que Xirau ejerce de filósofo riguroso. Piensa la educación desde su visión filosófica del mundo. Es una manera de señalar que la educación está en función de valores previos. ¿Cómo educar en política y en justicia, tal y como aquí han sido planteadas, es decir, no como politización sino como ejercicio responsable del ser humano que no renuncia a la razón ni a la moral en la construcción de la vida pública?

1. Se me ocurre pensar que el lugar de la educación es ese punto en el que se pierde la experiencia y comienza el conocimiento, el mundo de los conocimientos, de los conocimientos que tanto preocupan a los padres y a las autoridades políticas. La educación debería consistir en aprender lo que procede para ser un buen ciudadano y un hombre de provecho, pero sabiendo que partimos de una inmensa pérdida, pérdida que ningún conocimiento podrá llenar ni sustituir. Esa pérdida consiste en haber identificado la sabiduría con el conocimiento científico que se ha convertido en el primer analogado del saber. Vale aquí lo que decía Horkheimer a Paul Tillich: "que la ciencia es estadística y al conocimiento le basta un campo de concentración". ${ }^{26}$ La sabi-

${ }^{26}$ Apud Rolf Wiggershaus, Die Frankfurter Schule: Geschichte, Theoretische Entwicklung, Politische Bedeutung. Múnich, Hanser, 1986, p. 355. 
duría puede nacer y crecer en la experiencia, sobre todo en la experiencia negativa.

2. Que quede claro que no se trata de re-construir la experiencia perdida. Si esa experiencia estuvo una vez ligada al trivium (lógica, retórica y gramática), de poco vale dar más clases de latín o de filosofía o rescatar las humanidades tal y como una vez fueron. La era del relato ya pasó.

3. Eso no significa que nos tengamos que resignar con la transmisión de conocimientos útiles. Lo que nos queda o nos puede quedar es la conciencia de que la vivencia no es experiencia, ni el conocimiento es sabiduría. Lo que nos queda es la posibilidad de redimensionar lo que sabemos en un horizonte abierto. Quiero decir lo siguiente. Lo que se pierde en la forma adulta, madura o ilustrada del conocer es la infancia. In-fancia significa sin-lenguaje. En la infancia no hay lenguaje. Y cuando el hombre llega al lenguaje expulsa a la infancia. La infancia tiene que salir del lenguaje. El hombre, cada vez que habla, silencia, acalla todo un mundo sin palabras. Esa es la violencia del lenguaje que todo lo quiere poseer. La palabra es ratio y verbum. Ambas, también la ratio, no pueden convivir con la infancia.

Ahora bien, saber que hay in-fancia, es decir, una zona de experiencia prelingüística, lleva consigo saber que el lenguaje no lo es todo, que hay hombre más allá del verbum y de la ratio. La infancia no es sólo una edad sino también una dimensión de lo humano, una dimensión particularmente presente en tiempos de pérdida de experiencia. ${ }^{27}$ En tiempos de apoteosis del lenguaje (la moderna sabiduría es el logos científico, la política es Parlamento, la ética es discursiva, etcétera) no es fácil hacer valer el silencio por muy elocuente que éste sea. Pero esa sería la tarea de la educación: hacer valer la in-fancia como transcendencia del adulto. La in-fancia rebaja los humos del lenguaje al decirle que antes del lenguaje hay un silencio y que como no todo es lenguaje, después de haber dicho todo, queda lo más importante: lo que no se puede decir. El silencio al que nos referimos es el socrático: el que aparece después de haber dicho todo lo que hay que decir. Esa remisión de la palabra al silencio es posible gracias a la memoria del testigo que es la voz de los sin voz. Esa tarea, según Aranguren, era lo propio del intelectual; digamos que es lo propio del testigo.

4. Hubo un tiempo en que la educación, atenta a la etimología, se entendía como extracción de lo que cada cual llevaba dentro. Habría que reinterpretar la metáfora: lo que hay que sacar fuera y poner en evidencia es lo que no somos, lo que está ausente del ser que creemos ser. Ese giro hermenéutico debe afectar a la metáfora reina del conocimiento: para los griegos el conoci-

${ }^{27}$ Sobre este particular, véase G. Agamben, Enfance et histoire. París, Payot, 2000. 
miento era una visión, una theoría. La imagen de la visión evoca una luz interior que ilumina lo que nos rodea. Uno ve conforme a la luz que lo ilumina. Pero con la visión no salimos de nosotros mismos aunque podamos ver hasta muy lejos.

Aquí estamos abogando por un tipo de saber que nos viene de afuera, que nos invade, nos altera. La metáfora de ese saber sería el oído no el ojo, la escucha y no la visión. La educación como atención a lo que no somos, ni tenemos, pero sin lo que posiblemente no nos logremos. Educar sería hacer de cada ser humano un testigo que da constancia y validez de lo que queda silenciado en la palabra o en el conocimiento que circula por las autopistas de la información. 